\title{
ANALISA STRUKTUR KOMUNITAS HUTAN MANGROVE DI DESA PASAR SEBELAH KECAMATAN KOTA MUKOMUKO KABUPATEN MUKOMUKO
}

\author{
Oleh: \\ Zamdial $^{1}$ \\ ${ }^{1}$ Program Studi IImu Kelautan Fakultas Pertanian Universitas Bengkulu, \\ dan Ketua Konsorsium Mitra Bahari (KMB) Provinsi Bengkulu \\ *Email: zamdial_et@yahoo.co.id \\ Received August 2016, Accepted September 2016
}

\begin{abstract}
Dalam jangka panjang penelitian ini bertujuan untuk melestarikan sumberdaya ekosistemen hutan mangrove di Desa Pasar Sebelah Kecamatan Kota Mukomuko, Kabupaten Mukomuko agar tetap dapat memberikan fungsi ekologis dan ekonomi secara berkesinambungan. Secara khusus penelitian ini bertujuan untuk mendeskripsikan kondisi umum, menganalisis parameter lingkungan dan menganalisis struktur ekosistem hutan mangrove di Desa Pasar Sebelah Kecamatan Kota, Kabupaten Mukomuko.

Penelitian ini dilakukan dengan Metode Survai. Pengumpulan data parameter kualitas perairan dan hasil perikanan dilakukan dengan teknik observasi dan pengukuran langsung di lapangan. Pengumpulan data tegakan vegetasi mangrove menggunakan Metode Belt Transect dengan ukuran transek $10 \mathrm{~m} \times 10 \mathrm{~m}$. Pengolahan dan analisis data hasil penelitian menggunakan metode statistik deskripitif.

Hasil pengamatan terhadap komposisi jenis tumbuhan yang terdapat di ekosistem hutan mangrove Desa Pasar Sebelah menunjukkan bahwa hanya ada satu jenis tumbuhan mangrove yaitu jenis pedada/pidado (Sonneratia caesolaris) dengan Indeks Nilai Penting (INP) masing-masing stasiun adalah 191,23 (Stasiun I), 181,72 (Stasiun II) dan 205,07 (Stasiun III). Indeks Dominansi pada setiap stasiun adalah lebih kecil dari 1 (satu), yang menunjukkan tidak ada dominansi antar jenis.

Nilai rata-rata parameter perairan di ekosistem mangrove secara beruturut-turut adalah salinitas $(0,9 \%), \mathrm{pH}(6,90)$, suhu $\left(29,87^{\circ} \mathrm{C}\right), \mathrm{NO}_{3}(0,2367 \mathrm{mg} / \mathrm{l}), \mathrm{NO}_{2}(0,0208 \mathrm{mg} / \mathrm{l})$ dan $\mathrm{PO}_{4}(0,1451 \mathrm{mg} / \mathrm{l})$. Nilai parameter perairan di ekosistem hutan mangrove Desa Pasar Sebelah menunjukkan kondisi yang masih baik dan belum tercemar sehingga mendukung keberadaan ekosistem mangrove tersebut.
\end{abstract}

Keywords : community structure, mangrove, pasar sebelah, mukomuko

\section{PENDAHULUAN}

Desa Pasar Sebelah, Kecamatan Kota Mukomuko, merupakan salah satu desa pesisir yang terletak di Pantai Barat Kabupaten Mukomuko. Selain sumberdaya perairan pantai dan laut, Desa Pasar Sebelah juga memiliki potensi sumberdaya ekosistem hutan mangrove. Sepanjang pesisir Kabupaten Mukomuko ekosistem hutan mangrove hanya ada di beberapa tempat saja, yaitu di Muara Sungai Air Hitam, Muara Sungai Teramang, Desa Pasar Mukomuko, Desa Ujung Padang, Desa Bandar Ratu dan Desa Pasar Sebelah.

Ekosistem hutan mangrove di Desa Pasar Sebelah, yang tidak begitu luas merupakan daerah penangkapan (fishing ground) berbagai jenis ikan, udang dan kepiting, sebagai mata pencaharian sebagian masyarakat. Dan memang sejak dulu ekosistem hutan mangrove tersebut menjadi salah satu sumber perekonomian masyarakat. Menurut Departemen Kelautan dan Perikanan (2002), sumberdaya pesisir berperan penting dalam mendukung pembangunan ekonomi daerah dan nasional untuk meningkatkan 
penerimaan devisa negara, lapangan kerja, dan pendapatan penduduk. Dan Fauzi (2009) menambahkan, bahwa ekosistem pesisir selain berfungsi secara hidrobiologis, juga menyediakan manfaat ekonomi bagi masyarakat meski kita sendiri tidak menyadarinya.

Rusaknya ekosistem hutan mangrove memberikan dampak negatif terhadap ketersediaan sumberdaya ikan dan resiko banjir. Untuk Kabupaten Mukomuko, keberadaan hutan mangrove mempunyai arti yang lebih strategis dewasa ini, karena keberadaan hutan mangrove tersebut dapat menjadi pelindung bencana tsunami. Beberapa informasi dasar diperlukan dalam upaya pengelolaan dan pemanfaatan sumberdaya ekosistem hutan mangrove diantaranya adalah kondisi ekologi, gambaran masysrakat yang mengelola dan memanfaatkan potensi sumberdaya ekosistem hutan mangrove dan nilai-nilai ekonomi yang dapat diperoleh dari ekosistem hutan mangrove tersebut.

Penelitian ini bertujuan untuk mendeskripsikan kondisi umum, menganalisis parameter lingkungan dan menganalisis struktur ekosistem hutan mangrove di Desa Pasar Sebelah Kecamatan Kota, Kabupaten Mukomuko. Manfaat dari hasil penelitian ini antara lain adalah sebagai informasi tentang kondisi terkini ekosistem hutan mangrove di Desa Pasar Sebelah Kecamatan Kota, Kabupaten Mukomuko yang dapat dijadikan acuan dalam pemanfaatan dan pengelolaan potensi ekosistem hutan mangrove tersebut. Hasil penelitian ini juga dapat bermanfaat sebagai dasar untuk perencanaan program konservasi ekosistem hutan mangrove di Desa Pasar Sebelah Kecamatan Kota, Kabupaten Mukomuko baik oleh pihak pemerintah, masyarakat setempat maupun oleh pihak stakeholder lainnya.

\section{Tempat dan Waktu penelitian}

\section{METODE PENELITIAN}

Lokasi penelitian adalah ekosistem hutan mangrove di Desa Pasar Sebelah, Kecamatan Kota Mukomuko, Kabupaten Mukomuko, Provinsi Bengkulu. Waktu penelitian adalah pada bulan Agustus Tahun 2013.

Penelitian ini dilakukan dengan Metode Survai yang meliputi kegiatan observasi dan pengukuran langsung untuk mendapatkan data parameter lingkungan perairan, data jenis dan tegakan pohon mangrove. Beberapa data aspek sosial-budaya, terutama yang berkaitan dengan pemanfataan dan pengelolaan ekosistem hutan mangrove diperoleh dengan menggunakan metode wawancara terstruktur dan tidak terstruktur terhadap sampel/responden yang telah ditetapkan.

Data biofisik ekosistem hutan mangrove, meliputi data parameter fisika dan kimia, diambil dengan melakukan pengukuran langsung di lapangan. Pengukuran dilakukan pada stasiun-stasiun pengamatan yang ditetapkan secara proporsional.

Data plankton diambil dengan menggunakan jaring plankton pada stasiun-stasiun pengamatan yang telah ditetapkan. Khususnya untuk data tegakan vegetasi mangrove, pengamatan dilakukan dengan menggunakan Metoda Belt Transek yang diletakkan secara purposive, mulai dari pinggir ekosistem hutan mangrove ke arah darat. Lebar transek yang digunakan adalah $10 \mathrm{~m}$.

Data sekunder sebagai pendukung dan pembanding diperoleh dari berbagai instansi pemerintah, kelompok tani, Gapoktan, LSM da organisasi kemasyarakatan lainnya yang mempunyai keterkaitan dengan pemanfaatan, pengelolaan dan rehabilitasi ekosistem hutan mangrove.

\section{Pengolahan dan Analisia Data Biofisik}

Data parameter fisika, kimia dan biologi diolah secara kuantitatif dan kualitatif. Selanjutnya data tersebut dianalisis secara deskriptif-komparatif, yaitu menginterpretasi data dalam bentuk rata-rata. Analisas deskriptif kuantitatif adalah menginterpretasi data dengan melihat besaran data dan nilai rata-rata. Analisa analisa deskriptif kualitatif artinya menginterpretasi data dengan melihat penampakan kualitasnya. 


\section{HASIL DAN PEMBAHASAN \\ Komposisi dan Struktur Ekosistem Hutan Mangrove}

Luas kawasan ekosistem hutan mangrove Desa Pasar Sebelah Kecamatan Kota Mukomuko, Kabupaten Mukomuko adalah $\pm 13,5$ hektar (Zamdial, et al, 2015). Dan dari hasil pengukuran diketahui bahwa ekosistem mangrove di Desa Pasar Sebelah, panjangnya $\pm 2,7 \mathrm{~km}$ dan lebar rata-rata $50 \mathrm{~m}$. Ekosistem hutan mangrove ini sudah menjadi sumber penghidupan sebagian mansyarakat setempat sejak lama. Secara sosiologi, masyarakat sudah memahami pentingnya keberadaan ekosistem hutan mangrove baik bagi sumber mata pencaharian maupun sebagai pelindung dari abrasi, banjir dan tsunami.

Ada 3 (tiga) jenis tumbuhan pada ekosistem hutan mangrove di Desa Pasar Sebelah, yaitu Sonneratia caseolaris, tumbuhan nipah (Nypa fruticans) dan Crinum asiaticum. Jenis mangrove Sonneratia caseolaris dikalangan masyarakat setempat dikenal dengan nama pedada/pedado. Sonneratia caseolaris mendominasi semua tingkat pertumbuhan dan dijumpai pada semua stasiun pengamatan. Pada lokasi sampling 1 dan 2 ditemukan 2 jenis tumbuhan yaitu Sonneratia caseolaris dan tumbuhan nipah (Nipa fruticans), sedangkan pada lokasi sampling 3 ditemukan Sonneratia caseolaris, tumbuhan nipah (Nypa fruticans) dan Crinum asiaticum. Menurut Catherine (1993), tumbuhan mangrove jenis Sonneratia ada dua, yaitu Sonneratia alba dengan ciri-ciri antara lain mempunyai bunga warna putih dan Sonneratia caseolaris yang mempunyai bunga berwarna merah.
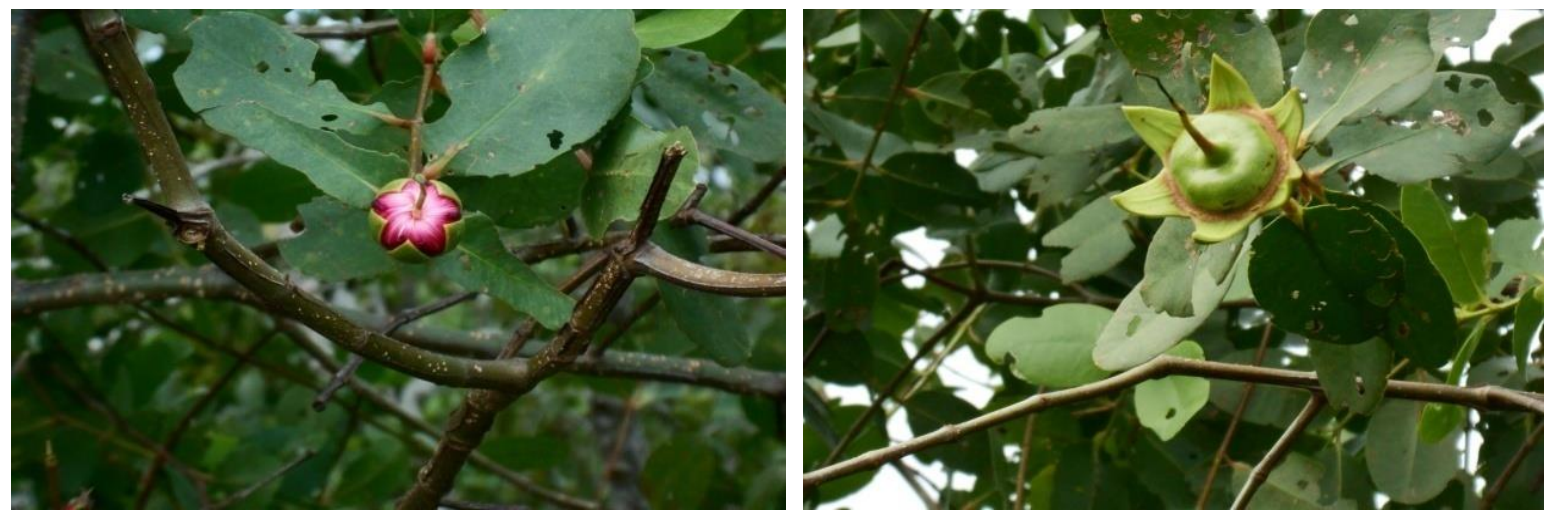

Gambar 1. Bentuk bunga (berwarna merah) dan buah (berwarna hijau) dari tumbuhan mangrove Sonneratia caseolaris di Desa Pasar Sebelah Kecamatan Kota Mukomuko Kabupaten Mukomuko

Adanya tumbuhan nipah pada ekosistem hutan mangrove di Desa Pasar Sebelah adalah hal yang biasanya, mengingat lingkungan ekosistem mangrove tersebut merupakan percampuran air tawar dan air laut. Menurut Kartawinata (2013), sepanjang aliran sungai dari hulu hingga uara, pada tanah yang padat yang dipengaruhi air pasang, hutan mangrove dapat didominasi oleh palem Nypa fructicans.

Ekosistem hutan mangrove di Desa Pasar Sebelah termasuk tipe riverine mangroves, karena ekosistem hutan mangrove tersebut ditemukan di bagian kanan dan kiri aliran Sungai Air Manjuto. Sesuai pendapat Ludo and Snedaker (1974) dalam Miththapala (2008), bahwa ada tiga jenis ekosistem mangrove yaitu riverine mangroves, fringe mangroves dan basin mangroves. Riverine mangroves, sesuai dengan namanya terdapat disepanjang sungai dan aliran sungai dan digenangi sepanjang hari oleh pasang surut. 
Lokasi ekosistem hutan mangrove di Desa Pasar Sebelah berada $\pm 2,5 \mathrm{~km}$ dari muara Sungai Air Manjuto. Pengaruh pasang surut dan aliran Sungai Air Manjuto membuat ekosistem hutan mangrove di Desa Pasar Sebelah selalu tergenang air. Volume air laut yang masuk dari Samudera Hindia tidak terlalu besar karena mulut muara sungai yang sangat kecil. Hal ini berpengaruh terhadap nilai salinitas air yang menggenangi ekosistem mangrove cukup rendah.
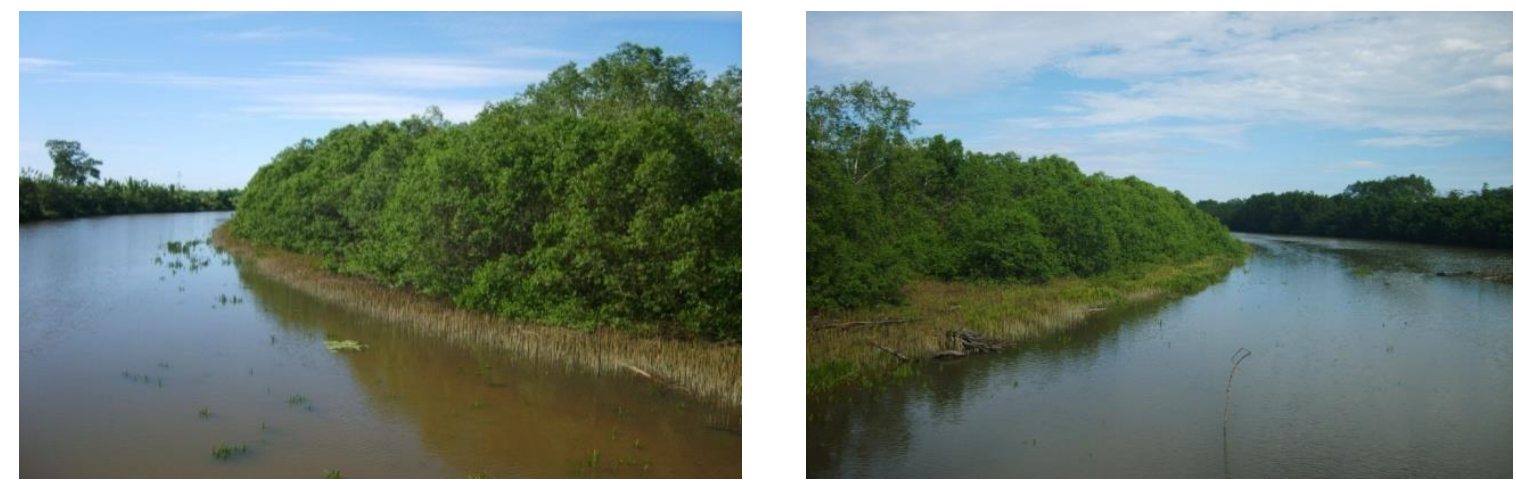

Gambar 2. Lokasi ekosistem hutan mangrove di Desa Pasar Sebelah yang terletak disepanjang aliran Sungai Air Manjuto

Hasil analisis data ekosistem mangrove di Desa Pasar Sebelah Kecamatan Kota Mukomuko Kabupaten Mukomuko ditampilkan pada Tabel 1 berikut ini.

Tabel 1. Struktur vegetasi dan nilai penting tingkat pohon tumbuhan mangrove di Desa Pasar Sebelah, Kecamatan Kota Mukomuko, Kabupaten Mukomuko

\begin{tabular}{|c|c|c|c|c|c|c|c|c|c|c|}
\hline Sampling & $\begin{array}{c}\text { Jenis } \\
\text { Tumbuhan }\end{array}$ & Di & $\mathrm{RDi}$ & $\mathrm{Fi}$ & $\mathrm{RFi}$ & $\mathrm{Ci}$ & $\mathrm{RCi}$ & INP & $D$ & $\mathrm{H}^{\prime}$ \\
\hline \multirow{2}{*}{ Sampling 1} & $\begin{array}{l}\text { Sonneratia } \\
\text { caseolaris }\end{array}$ & 0,22 & 57,89 & 1 & 33,33 & 56,13 & 100 & 191,23 & 0,34 & 0,32 \\
\hline & $\begin{array}{l}\text { Nipa } \\
\text { fruticans }\end{array}$ & 0,16 & 42,11 & 1 & 33,33 & & & & 0,18 & 0,36 \\
\hline \multirow{2}{*}{ Sampling 2} & $\begin{array}{l}\text { Sonneratia } \\
\text { caseolaris }\end{array}$ & 0,15 & 48,39 & 1 & 33,33 & 32,20 & 100 & 181,72 & 0,23 & 0,35 \\
\hline & $\begin{array}{l}\text { Nipa } \\
\text { fruticans }\end{array}$ & 0,16 & 51,61 & 1 & 33,33 & & & & 0,27 & 0,34 \\
\hline \multirow{3}{*}{ Sampling 3} & $\begin{array}{l}\text { Sonneratia } \\
\text { caseolaris }\end{array}$ & 0,33 & 71,74 & 1 & 33,33 & 48,99 & 100 & 205,07 & 0,51 & 0,24 \\
\hline & $\begin{array}{l}\text { Nipa } \\
\text { fruticans }\end{array}$ & 0,07 & 15,22 & 1 & 33,33 & & & & 0,02 & 0,29 \\
\hline & $\begin{array}{l}\text { Crinum } \\
\text { asiaticum }\end{array}$ & 0,06 & 13,04 & 1 & 33,33 & & & & 0,02 & 0,27 \\
\hline
\end{tabular}

Keterangan : Di : Kerapatan Jenis; RDi : Kerapatan Relatif; Fi : Frekuensi Jenis; RFi : Frekuensi Relatif; Ci : Penutupan Jenis ; RCi : Penutup Relatif; INP: Indeks Nilai Penting ; D : Indeks Dominansi; H' : Indeks Keanekaragaman

Berdasarkan Tabel 2 diatas, dapat diketahui perbedaan pada masing-masing nilai kerapatan relatif ( $\mathrm{RDi}$ ) pada setiap stasiun pengamatan, pada sampling 1 memiliki kerapatan jenis yang lebih besar yaitu 57,89 pada jenis Sonneratia caseolaris, pada sampling II 48,39, dan sampling III 71,74. Untuk Frekuensi relatif, memiliki nilai yang sama yaitu 33,33 yang menunjukkan bahwa penyebaran dan keberadaan jenis tiap mangrove 
ditemukan di seluruh wilayah sampling pengamatan. Untuk penutupan relatif pada sampling I menunjukkan nilai yang lebih besar yaitu pada jenis Sonneratia caseolaris yaitu 56,13 dibandingkan pada sampling II 32,30 dan sampling III 48,99. Hal ini menunjukkan bahwa Sonneratia caseolaris lebih banyak mendominasi pada sampling I.

Untuk Nilai Indeks Penting (INP), Sonneratia caseolaris pada sampling I $(191,23)$, pada sampling II $(181,72)$, pada sampling III $(205,07)$, Hal ini menunjukkan bahwa pada sampling 3 untuk jenis Sonneratia caseolaris memiliki peranan yang lebih besar untuk menjaga keberlangsungan ekosistem. Untuk nilai indeks dominansi, nilai pada keseluruhan stasiun adalah 0 , Hal ini menunjukkan bahwa tidak terdapat jenis yang mendominasi jenis lainnya atau komunitas berada dalam kondisi stabil. Sedangkan nilai indeks keanekaragaman jenis pada seluruh wilayah sampling memiliki jenis keanekaragaman yang rendah yaitu $0<\mathrm{H}<2$.

Hasil analisis vegetasi untuk tingkat pohon dapat diketahui bahwa pada lokasi penelitian hanya terdapat satu jenis tumbuhan mangrove yaitu Sonneratia caseolaris. Indek Nilai Penting (INP) secara berturut-turut adalah 191,23 (lokasi sampling 1), 181,72 (lokasi sampling 2) dan 205,07 (lokasi sampling 3).

\section{Parameter Ekologi Ekosistem Hutan Mangrove}

Tabel 2. Data hasil pengukuran fisik perairan ekosistem mangrove di Desa Pasar Sebelah Kecamatan Kota Mukomuko, Kabupaten Mukomuko

\begin{tabular}{|c|c|c|c|c|c|c|c|}
\hline $\begin{array}{c}\text { No. Stasiun } \\
\text { GPS }\end{array}$ & $\begin{array}{c}\text { Salinitas } \\
(\% \circ)\end{array}$ & $\mathrm{pH}$ & $\begin{array}{c}\text { Suhu } \\
\left({ }^{\circ} \mathrm{C}\right)\end{array}$ & $\begin{array}{c}\mathrm{NO}_{3} \\
(\mathrm{mg} / \mathrm{l})\end{array}$ & $\begin{array}{c}\mathrm{NO}_{2} \\
(\mathrm{mg} / \mathrm{l})\end{array}$ & $\begin{array}{c}\mathrm{PO}_{4} \\
(\mathrm{mg} / \mathrm{l})\end{array}$ & $\begin{array}{c}\text { Jarak } \\
(\mathrm{m})\end{array}$ \\
\hline 135 & 2,0 & 6,88 & 30,6 & 0,0523 & 0,0037 & 0,0982 & $\pm 5 \mathrm{~m}$ \\
\hline 136 & 1,0 & 6,94 & 30,7 & 0,0883 & 0,0072 & 0,0914 & $\pm 5 \mathrm{~m}$ \\
\hline 137 & 1,0 & 6,96 & 30,4 & 0,0994 & 0,0087 & 0,0803 & $\pm 5 \mathrm{~m}$ \\
\hline 138 & 1,0 & 6,80 & 29,8 & 0,0929 & 0,0114 & 0,2392 & $\pm 5 \mathrm{~m}$ \\
\hline 139 & 0,1 & 6,88 & 29,1 & 0,2036 & 0,0205 & 0,1340 & $\pm 5 \mathrm{~m}$ \\
\hline 140 & 0,1 & 6,92 & 28,6 & 0,8839 & 0,0732 & 0,2274 & $\pm 5 \mathrm{~m}$ \\
\hline Rata-rata & 0,9 & 6,90 & 29,87 & 0,2367 & 0,0208 & 0,1451 & $\pm 5 \mathrm{~m}$ \\
\hline
\end{tabular}

Sumber : Data hasil pengukuran di lapangan, 4 September 2013.

Pada Tabel 2 dapat diketahui nilai beberapa parameter fisik perairan di kawasan ekositem mangrove di Desa Pasar Sebelah Kecamatan Kota Mukomuko, Kabupaten Mukomuko. Nilai parameter fisik tersebut merupakan indikator dari kondisi perairan di kawasan ekosistem mangrove saat ini.

Nilai salinitas perairan di lokasi penelitian berkisar antara $0,1-2,0 \%$ dengan nilai rata-rata $0,9 \%$. Rendahnya nilai salinitas perairan dikarenakan besarnya pengaruh air tawar dari aliran Sungai Air Manjuto. Dan pada saat didilakukan pengukuran data salinitas perairan bertepatan dengan berlangsung musim penghujan.

Kondisi salinitas perairan yang rendah menjadi indikator keberadaan jenis tumbuhan mangrove yang didominasi oleh Sonneratia caseolaris atau pedada. Tumbuhan mangrove umumnya dapat beradapatasi dan mempunyai toleransi yang tinggi terhadap kondisi salinitas perairan dibandingkan tumbuhan yang bukan mangrove. Sebagai contoh semaian Rhizophora mucronata dapat tumbuh baik pada salinitas $30 \%$ dan $R$. apiculata dapat tumbuh pada salinitas $15 \%$ (Kathiresan et al, 1996). Berbeda halnya dengan tumbuhan mangrove jenis Sonneratia $s p$ yang mampu mentoleransi kondisi salinitas 
perairan yang lebih rendah. Sebagaimana pendapat MacNae (1968) dalam Pramudji (2001), bahwa Avicennia marina mapu tumbuh pada salinitas sangat tinggi sampai $90 \%$ sedangkan Sonneratia sp umumnya hidup pada salinitas yang tinggi, kecuali Sonneratia caesolaris yang dapat hidup pada salinitas perairan sekitar $10 \%$. Selanjutnya Ball and Pidsley (1995) juga menegaskan, bahwa Sonneratia alba dapat tumbuh pada perairan dengan kisaran salinitas 2-18 \%, dan Sonneratia lanceolata hanya toleran terhadap salinitas perairan sampai $2 \%$.

Indikator kondisi perairan yang berkaitan dengan perikanan dilihat dari parameter $\mathrm{pH}$ dan kandungan nitrit $\left(\mathrm{NO}_{2}\right)$, nitrat $\left(\mathrm{NO}_{3}\right)$ dan phosphat $\left(\mathrm{PO}_{4}\right)$ dalam air. Nilai rata-rata $\mathrm{pH} 6,90$, nilai kandungan nitrit rata-rata 0,0208 , nilai kandungan rata-rata nitrat 0,2367 dan kandungan rata-rata phosphat 0,1451 menunjukkan kualitas air yang baik untuk keperluan perikanan, dan juga menunjukkan kondisi perairan yang belum tercemar. Hal ini sesuai dengan penjelasan Alaerts dan Santika (1984), bahwa kualitas air yang baik untuk perikanan ditunjukkan oleh nilai $\mathrm{pH}(6-9)$, kandungan nitrit dalam air (0,06 mg/l), sedangkan mutu air yang baik dan belum tidak tercemar ditunjukkan oleh nilai pH perairan (6-9), kandungan nitrat $(10 \mathrm{mg} / \mathrm{l})$ dan kandungan nitrit $(1 \mathrm{mg} / \mathrm{l})$. Sementara itu menurut Wardhana (2004), baku mutu air yang baik untuk perikanan ditandai dengan nilai kandungan nitrat $5 \mathrm{mg} / \mathrm{l}$ dan phosphate $0,5 \mathrm{mg} / \mathrm{l}$.

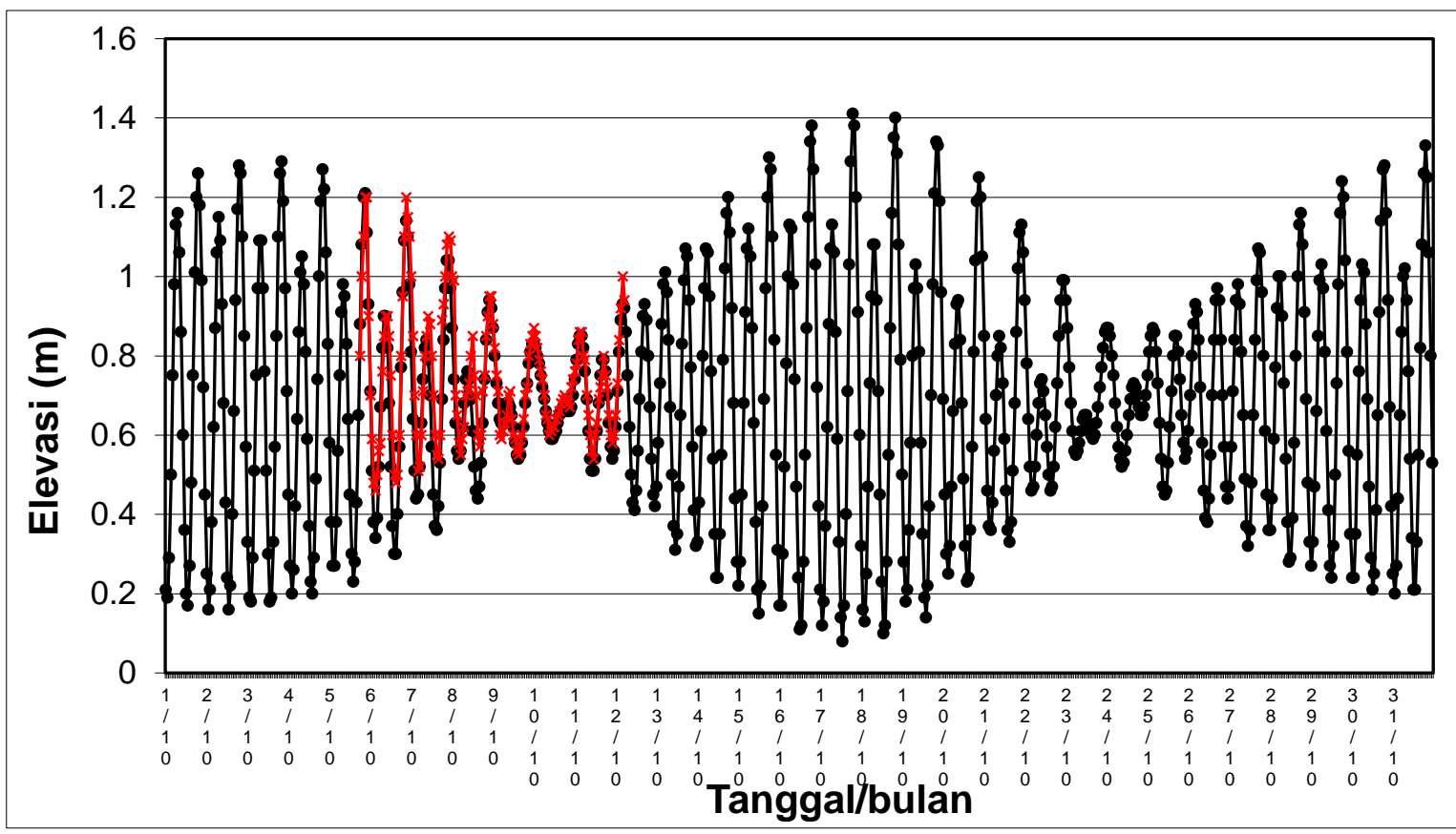

Keterangan: Garis dan titik hitam bersumber dari data pasut Dishidros. Garis dan titik merah bersumber data primer

Gambar 3. Grafik pasang surut di perairan sekitar loksai ekosistem hutan mangrove di Desa Pasar Sebelah, Kecamatan Kota Mukomuko, Kabupaten Mukomuko

Berdasarkan hasil pengukuran pasang surut dan diverifikasi dengan data pasang surut yang dikeluarkan Dishidros TNI-AL 2012, maka diperoleh data paramter pasut sebagai baerikut :

- HW (Highest Water) : Nilai kondisi muka air tertinggi =1.41 meter

- MHHWL (Mean High Highest Water Level) : Nilai rata-rata muka air tinggi tertinggi = 1.23 meter

- MHWL (Mean High Water Leve) : Nilai rata-rata muka air tinggi =1.05 meter

- MSL (Mean Sea Level) : Nilai rata-rata kondisi muka air $=0.69$ meter

- MLWL (Mean Low Water Level) : Nilai rata-rata muka air rendah = 0.38 meter 
- MLLWL(Mean Low Lowest Water Level) : Nilai rata-rata muka air rendah terendah = 0.23 meter

- LW (Lowest Water) : Nilai terendah muka air = 0.08 meter

- Tidal Range: Tunggang Pasut $=1.33$ meter

\section{KESIMPULAN DAN SARAN Kesimpulan}

Kondisi biofisik ekosistem mangrove di Desa Pasar Sebelah, Kabupaten Mukomuko masih dalam keadaan baik dan belum terindikasi adanya pencemaran, sehingga mampu mendukung pertumbuhan dan perkembangan flora dan fauna yang hidup di lingkungan ekosistem mangrove tersebut.

3. Ekosistem mangrove dimanfaatkan untuk sumber produksi kepiting, udang dan ikan, serta pembuatan tambak untuk ikan nila dan pemeliharaan kepiting bakau dengan sistem karamba.

4. Nilai ekonomi ekosistem mangrove mangrove di Desa Pasar Sebelah, Kabupaten Mukomuko yang dimanfaatkan secara langsung oleh masyarakat adalah perikanan tangkap dan perikanan budidaya, sedangkan nilai manfaat tidak langsung adalah nilai penaham abrasi dan banjir, nilai sebagai penyedia unsur hara, nilai manfaat pilihan dan nilai manfaat keberadaan.

5. Nilai manfaat langsung perikanan tangkap dari ekosistem hutan mangrove di Desa Pasar Sebelah, Kabupaten Mukomuko adalah Rp. 937.295.000,- per tahun atau Rp. 69.429.259,- per hektar per tahun, nilai manfaat dari kegiatan budidaya ikan dalam tambak adalah sebesar Rp. 214.400.000,- per tahun, nilai manfaat tidak langsung adalah Rp. 835.699.059,- per tahun atau Rp. 61.903.634,- per hektar/tahun, sedangkan nilai manfaat total adalah Rp. 1.772.994.059,- per tahun atau Rp. 130.782.893,- per hektar per tahun. Nilai manfaat langsung lebih besar dibandingkan nilai manfaat tidak langsung yaitu $53,64 \%$.

6. Hasil penilaian keberadaan (Performa) ekosistem hutan mangrove di Desa Pasar Sebelah, menunjukkan kondisi ekosistem hutan mangrove yang lebih dari asli, indah, memberikan kondisi nyaman, dan sangat didukung oleh aspirasi masyarakat.

7. Potensi ekosistem hutan mangrove di Desa Pasar Sebelah adalah terdiri dari luasan ekosistem hutan mangriove yang masih stabil ( $\pm 13,5$ hektar), potensi sumberdaya hayati berupa berbagai jenis ikan, kepiting dan udang, potensi perikanan budidaya, potensi buah pedado sebagai sumber bahan pangan, dan juga potensi wisata lokal.

8. Alternatif pemanfaatan potensi ekosistem hutan mangrove yang dapat dikembangkan kedepan adalah budidaya ikan, udang dan kepiting bakau dalam tambak, budidaya ikan betutu, pengolahan buah pedada menjadi berbagai produk pangan dan obyek wisata lokal.

\section{Saran}

Untuk melengkapi data potensi sumberdaya hayati perikanan di ekosistem hutan mangrove di Desa Pasar Sebelah perlu dilakukan penelitian lanjutan tentang kelimpahan dan keanekargaman jenis ikan.

Untuk menjaga kelestarian ekosistem hutan mangrove di Desa Pasar Sebelah, perlu dibentuk Kelompok Pengelola/Pencinta Mangrove, pemasangan papan merek sebagai rambu-rambu untuk menghindari agar tidak terjadi pengrusakan flora, fauna dan pencemaran lingkungan ekosistem hutan mangrove baik dengan disengaja maupun tidak di sengaja. 


\section{DAFTAR PUSTAKA}

Alaerts, G. dan Santika S. Sumantri, 1984. Metoda Penelitian Air. Penerbit Usaha Nasional Surabaya. 309 pp.

Ball, M.C. dan Pidsley, S.M., 1995. Growth Responses to Salinity in Relation to Distribution of Two mangroves Species, Sonneratia alba and Sonneratia lanceolata, in Nothern Australia. Funtional Ecology, 9 (1) : 77-85.

Bappeda Kabupaten Mukomuko, 2006. Rencana Strategis Pengelolaan Wilayah Pesisir dan Laut Kabupaten Mukomuko. Bappeda Kabupaten Mukomuko dan Universitas Bengkulu.

Bappeda dan BPS Kabupaten Mukomuko, 2012. Kecamatan Mukomuko Dalam Angka 2012. Bappeda dan BPS Kabupaten Mukomuko.

Catherine, L., 1993. Field Guide to the Mangroves of Queensland. Published by the Australian Institute of Marine Science. 48 p.

Departemen Kelautan dan Perikanan, 2002. Keputusan Menteri Kelautan dan Perikanan Nomor : Kep.10/MEN/2002 Tentang Pedoman Umum Perencanaan Pengelolaan Pesisir Terpadu. DKP, Jakarta.

Fauzi, A., 2009. Menakar Nilai Ekonomi Kawasan Pesisir. Buletin Tata Ruang. Edisi September-Oktober 2009. Hal. 15-18. Badan Koordinasi Penataan Ruang Nasional (BKPRN), Jakarta.

Kartawinata , K., 2013. Diversitas Ekosistem Alam Indonesia. LIPI Press Bekerja Sama dengan Yayasan Pustaka Obor Indonesia, Jakarta. 124 hal.

Kathiresan, K., Rajendran, N. dan Thangadurai, G., 1996. Growth of Mangrove Seedling in Intertidal Area of Vellar estuary Southeast Coast of India. Indian Journal of Marine Sciences, $25: 240-243$.

Miththapala, S., 2008. Mangroves. Coastal Ecosystem Series (Volume 2). Published by Ecosystems and Livelihoods Groups Asia, IUCN. Colombo. 29 p.

Wardhana, W. Arya, 2004. Dampak Pencemaran Lingkungan. Edisi Revisi. Penerbit Andi, Yogyakarta. 459 hal.

Zamdial T., D. Hartono, D. Bakhtiar, Nasir Ahmad dan B. Sulistyo, 2003. Peta Potensi Kelautan dan Perikanan Propinsi Bengkulu. Badan Penelitian dan Pengembangan (Balitbang) Pemerintah Propinsi Bengkulu. 87 hal.

Zamdial, Deddy Bakhtiar dan Dewi Purnama, 2015. Valuasi Ekonomi Ekosistem Hutan Mangrove di Desa Pasar SebelahKecamatan Kota Mukomuko Kabupaten Mukomuko. Jurnal Mitra Bahari, Vol. 10 No. 2, Juli-Desember 2015; 64-76. 


\section{Lampiran 1. Dokumentasi kegiatan survai pengambilan data}
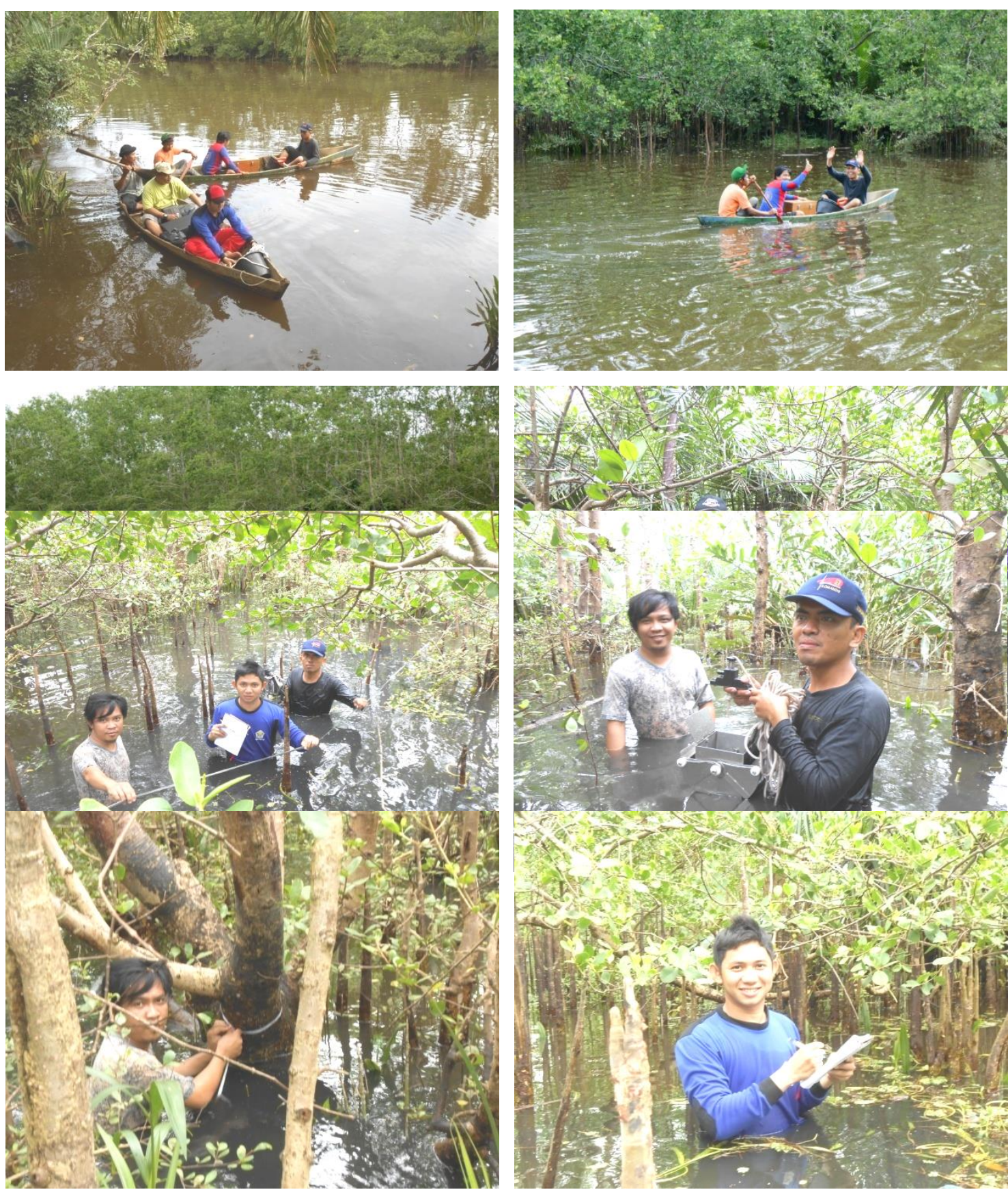